International Journal of Medical Arts 2020; 2 [2]: 373-384.

Available online at Journal Website
https://ijma.journals.ekb.eg/
Main subject [Surgery [General Surgery] ${ }^{*}$

Original article

\title{
Benefits and Risks of Laparoscopic Gastric Surgery for Management of Morbidly Obese Patients
}

\author{
Ahmed Salama Sayyouh ${ }^{\mathbf{a}}$; Ayman Mahmoud Elwan ${ }^{\mathbf{a}}$; Rabea Abdelghaffar Hassan ${ }^{\mathbf{b}}$ \\ Department of General Surgery, Damietta Faculty of Medicine, Al-Azhar University, Egypt[a]. \\ Department of General Surgery, Damietta General Hospital, Ministry of Health, Egypt ${ }^{[\mathbf{b}]}$.
}

Corresponding author: Rabea Abdelghaffar Hassan

Email: rabea.hsurg@domazhermedicine.edu.eg

Received at: January 28, 2020; Revised at: April 17, 2020; Accepted at: April 17, 2020; Available online at: April 17, 2020

DOI: 10.21608/ijma.2020.23146.1091

\begin{abstract}
Background: Conservative management for obesity had limited role in treatment of obesity. Otherwise, surgical treatment is effective, But associated with many comorbidities.

Aim of the work: To evaluate laparoscopic sleeve gastrectomy, greater curvature plication and gastric bypass in morbidly obese patients.

Patients and Methods: Thirty patients were included. They were divided into three groups: A for laparoscopic greater curvature plication, B for laparoscopic sleeve gastrectomy, and C for laparoscopic gastric bypass. All subjects underwent full history taking, clinical examination, laboratory investigations, abdominal ultrasonography, and upper gastrointestinal endoscopy. Follow up carried out at the first two weeks then at 1, 3, 6, 12 months for late postoperative complications, changes in comorbidities [hypertension, diabetes mellitus, arthritis] and percentage of excess weight loss.

Results: Studied groups were comparable as regard to patient demographics, preoperative comorbidities, intraoperative bleeding or postoperative complications. Operative time was significantly decreased in group B. estimated body weight loss [EBWL] differ significantly between groups at all postoperative follow up visits. For example at the second postoperative week, there was significant increase of EBWL in groups $B$ and $C$ when compared to group $A$ [5.75 \pm 3.96 and $8.4 \pm 5.54$ vs $1.15 \pm 0.81$ respectively]. Failure was $40 \%, 10 \%$ and $0 \%$ in groups $A, B$ and $C$ respectively. Only one patients died after operation in the bypass group. Morbidities were improved after surgery.

Conclusion: Laparoscopic greater curvature plication, is lower than laparoscopic sleeve gastrectomy and laparoscopic gastric bypass surgery as the procedure for weight loss, despite of its less cost. In addition, it had higher complications, reoperations and weight gains.
\end{abstract}

Keywords: Obesity; Barriatric surgery; Gastrectomy; Sleeve; Bypass.

This is an open access article under the Creative Commons license [CC BY] [https://creativecommons.org/licenses/by/2.0/]

Please cite this article as: Sayyouh AS, Elwan AM, Hassan RA. Benefits and Risks of Laparoscopic Gastric Surgery for Management of Morbidly Obese Patients. IJMA 2020; 2[2]: 373-384.

* Main subject and any subcategories have been classified according to researchers' main field of study. 


\section{INTRODUCTION}

Obesity reaches an epidemic level throughout the developed, as well as many of developing countries. This could be attributed to changes in diet habits and a more sedentary lifestyle. The World Health Organization [WHO] defined obesity as a body mass index $[\mathrm{BMI}] \geq 30 \mathrm{~kg} / \mathrm{m}^{2}$. Obesity itself is further subcategorized into class-I [30-34.9], class-II [35-39.9], and class- $-1 I I \geq 40 \mathrm{~kg} / \mathrm{m}^{2}$. Morbid obesity was defined if BMl was 40-49.9, super-obesity 50-59.9, and super-super-obesity $\geq 60 \mathrm{~kg} / \mathrm{m}^{2}$. Many comorbidities were attributed to morbid obesity, with earlier mortality. They include: coronary artery disease, hypertension, impaired cardiac ventricular function, adult-onset diabetes mellitus, hypoventilation and sleep apnea syndromes ${ }^{[1]}$. Conservative treatment measures seems to be insufficient for severe or morbid obesity. However, bariatric surgery appears to be adequate alternative, as it is associated with good long-term outcome [e.g., weight-loss and maintenance, reduction of co-morbidities and improved quality of life [2]. The principal mechanisms through which bariatric surgery attains its outcomes are believed to be the mechanical restriction of food intake, reduction of absorption of ingested foods, or a combination of both. Commonly restrictive techniques are adjustable gastric banding and vertical sleeve gastrectomy[3]. These procedures have proven to be good therapeutic options for some patients. However, they are not without significant complications $[4,5]$. Sleeve gastrectomy has gained vast popularity as sole bariatric intervention, based on the positive short and intermediate-term outcomes. In the past, sleeve gastrectomy was performed only in high-risk patients or as the first part in a two-step approach. Nowadays, sleeve gastrectomy has joined laparoscopic adjustable gastric band, Roux-en-Y gastric bypass, biliopancreatic diversion and bilio-pancreatic diversion with duodenal switch as bariatric procedure ${ }^{[6]}$. Sleeve gastrectomy works to reduce weight through a combination of restrictive and hormonal mechanisms. The residual sleeve, which is formed by the lesser curvature, has low compliance thus causing significant restriction and early satiety. In addition, the level of ghrelin hormone is reduced thus causing appetite reduction. SG is technically easier to perform $[7,8]$.
According to Talebpour and Amoli [9], the percentage of excessive weight loss in total gastric vertical plication in morbid obesity is comparable to other restrictive methods, but excessive weight loss appears more rapidly and early postoperative complications of this method are minimal without any important late complications. Brethaue et al.[10], suggested that a reduction in gastric capacity can be achieved by way of plication of the anterior stomach and greater curvature. The early weight loss results have been encouraging, with better weight loss in patients who underwent greater curvature plication. According to Ramos et al..[11], laparoscopic greater curvature plication is a bariatric weight loss procedure similar to vertical sleeve gastrectomy but without the need for gastric resection or disruption to normal anatomy.

The gastric bypass, in its various forms, accounts for a large majority of the bariatric surgical procedures performed. It is estimated that 200,000 of such operations were performed in the United States in 2008[12]. In Roux en-Y Gastric bypass, small intestine is divided approximately $45 \mathrm{~cm}$ below duodeno-jejunal junction and re-arranged into a $Y$ configuration, enabling outflow of food from the small upper stomach pouch via a "Roux limb". The Roux limb is constructed using $80-150 \mathrm{~cm}$ of the small intestine, preserving the rest of it to absorb nutrients[13]. Laparoscopic greater curvature plication [LGCP] causes reductions of the gastric volume by plication of the greater curvature result in gastric tube formation similar to that of LSG[14].The LGCP leads to good hunger control[10]. LSG leads to long lasting weight reduction and improvement of co-morbidities of the obesity, especially type-2 diabetes, because of at least two mechanisms, first reduced alimentary intake secondary to decreasing of stomach volume; second anorexia secondary to a fall in the orexigenic hormone, ghrelin[15]. LSG does not lead to malabsorption, but due to, resection of the gastric fundus [the main area of ghrelin production]. This consequently reduces the sensation of hunger ${ }^{[16]}$. The excess weight loss [EWL] is ranging between 60 and $70 \%$, one year following LRYGB, with this weight reduction being maintained at five years after the operation [17].All patients who underwent LRYGB reduced their diabetic medication requirements, and $78 \%$ were resolved by one year ${ }^{[18]}$. 
As morbid obesity is a rising problem among our society, and laparoscopic bariatric procedures are usually applied in non-morbid obese patients. We intended to evaluate different laparoscopic bariatric surgeries for morbid obesity and present our experience among such populations.

\section{AIM OF THE WORK}

The aim of this work is to evaluate the benefits and risks of laparoscopic gastric surgery including the impact upon the stomach in sleeve gastrectomy, greater curvature plication \& gastric bypass, in morbidly obese patients.

\section{PATIENTS AND METHODS}

This study was conducted at Al-Azhar University Hospital [New Damietta] from November 2016 to October 2019.Thirty patients were included in the study [we used the convenient sampling technique]. They were randomlay divided into three groups, and each group included ten patients: Group [A] underwent laparoscopic greater curvature plication, Group [B] underwent laparoscopic sleeve gastrectomy, and Group [C] underwent laparoscopic gastric bypass.

The inclusion criteria were: Obese individuals with $\mathrm{BMI} \geq 40 \mathrm{~kg} / \mathrm{m}^{2}$ or $35 \mathrm{~kg} / \mathrm{m}^{2}$ with co- morbidities, patient age extends between 18 and 50 years old, and no cardiopulmonary contraindication for surgery. On the other side, the exclusion criteria were: previous barietric surgery, psychological instability, sever gastric or esophageal ulceration, and endocrinal disorders.

Preoperatively, all subjects underwent full history taking, clinical examination, laboratoy investigations [complete blood picture, bleeding time, clotting time, internaional normaliztion ratio [INR], liver function tests and kidney function tests, fasting and postprandial blood glucose level, thyroid stimulating hormone [TSH], am and pm serum cortisol, total cholesterol and triglycerides levels], electro- and echo-cardiography, respiratory function tests, .abdominal ultrasonography, and upper gastrointestinal [GIT] endoscopy. All patient received preoperative low molecular weight heparin for prophylaxis against deep vein thrombosis.
Ethical consideration: A fully informed written consent had been taken from all patients after a comprehesive discussion with them about the operative procedure and the possible intra- and postoperative complications.

Operative details: All patients received antibiotic prophylaxis befor incision in the from of third generation cephalosporins. All operations were carried out under genaral anesthesia with endotracheal intubation. Then, a nasogastric tube was inserted, elastic stocking was applied to both patient's legs, and patient postioned in $15-30^{\circ}$ antiTrendlenberg tilt with both arms and thighs abducted and the surgeon standing between patient's legs. The patient was secured at the waist with table straps.

The steps for greater curvature plication and sleeve gastrectomy: Access to the peritoneum was achieved through aclosed technique or optical trocar with apressure setting of $14-15 \mathrm{mmHg}$. Ports were: one $10 \mathrm{~mm}$ optical port at a point between upper $2 / 3$ and lower $1 / 3$ of aline connenting xiphoid process and umbilicus for the $30^{\circ}$ laparoscope, one $12 \mathrm{~mm}$ port in the right upper quadrant at the right mid clavicular line for the surgeon's right hand, one $5 \mathrm{~mm}$ port in the left anterior axillary line 3-4cm below the costal margin for the surgeon's assistant, one $5 \mathrm{~m}$ port below the xiphoid process for the liver retractor, one $12 \mathrm{~mm}$ port in the left upper quadrant for the surgeon's left hand. Using a vessel sealing device, dissection of the gastric greater curvature was started at a point $3-4 \mathrm{~cm}$ proximal the pylorus and then extended upwards until the angle of His with careful dissection dowen to the left crus [Figure 1].Ingastric plication we dissect alittle away from the stomach. Careful dissection of any posterior gastric adhesion was done. Calibration was achieved by passing aved by passing a 36-Fr oro- gastric bougie towards the pylorus.

Laparoscopic gastric curvature plication: After introducing of the calibration bougie, plication was commenced by applying 2 rows of extramucosal sutures. The first row was composed of interrupted stitches of 2-non absorbable sutures. The sutures were taken at $2 \mathrm{~cm}$ interval distance. Each suture was taken by 2 bites on either sides of the great curvaturein order to achieve aplication rather 
than a simple imbrication of the great curve [Figure 2]. The seconed row was composed of continuous running non absorbable sutures .The seconed row must cover the first row [Figure 3]. Upper gastrointestinal endoscopy was performed to assess the final gastric capacity. Drain was placed at the left sub diaphragmatic space alongside the gastric pouch. Wounds were closed.

Laparoscopic Sleeve Gastrectomy: The transection of the stomach was started $4 \mathrm{~cm}$ proximal to the pylorus by a linear stapler [Figure 4], proper stapling gastric thick tissue; five to six firings were required to divide the entire stomach including the fundus. Re-enforcement of the staple line with a running suture or clips when needed. The stapled line was examined for leak by introduction of diluted methylene blue conducted in an 18-Fr nasogastric tube with the pyloro-duodenal junction compressed distal to it, making sure that the stapled line is water tight [Figure 5]. Drain was placed at the left sub diaphragmatic space alongside the gastric pouch. The resected stomach was removed from $12 \mathrm{~mm}$
port.Wounds were closed.

Laparoscopic Roux-en-Y Gastric ByPass: Oro-gastic was used to calibrate the proximal gastric pouch to about $15-20 \mathrm{ml}$. Enter the lesser sac from lesser omentum between second and third bracches of left gastric artery. Divide the stomach by sequential application of alinear endoscopic stapler to produce avertically oriented proximal gastic pouch [Figure 6]. Identification the ligament of Treitz, and division of the jejunum 30 to $50 \mathrm{~cm}$ distally with alinear stapler. A150cm Roux limb was fashioned \&side to side jejunostomy with linear stapler was created. The end of the Roux limb was passed into proximity to the gastric pouch, this may be done in either on antecolic or retrocolic fashion. The vessel sealing device was used to create gastrostomy [Figure 7] and enterotomy through which the linear stapler was passed and fired to create anastomosis [Figure 8].The remaining opening was then closed with two layers of running sutures. Leak test was done with methylene blue solution. Drain was inserted, then closure of the wounds.

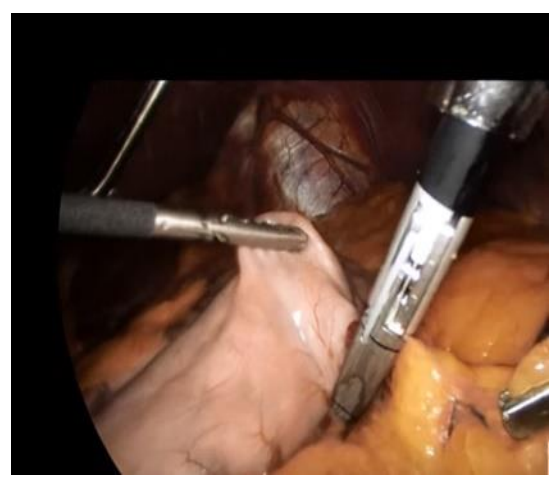

Figure [1]: A vessel sealing device was used to dissect of the gastric greater curvature at a point $3-4 \mathrm{~cm}$ proximal the pylorus.

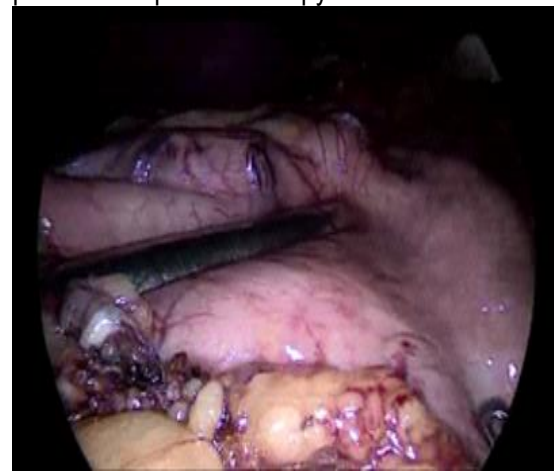

Figure [4]: Transection of the stomach proximal to the pylorus by a linear stapler.

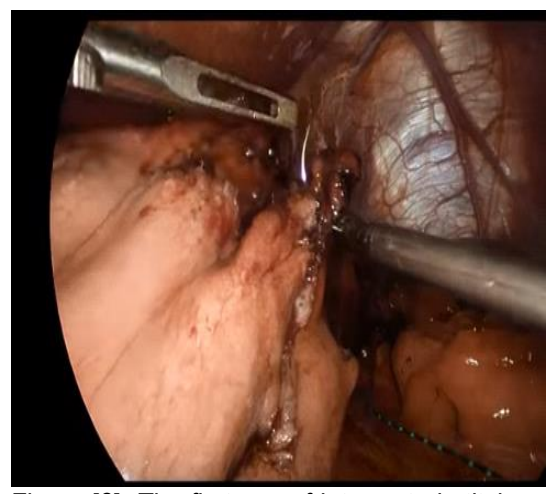

Figure [2]: The first row of interrupted stitches of 2-non absorbable sutures.

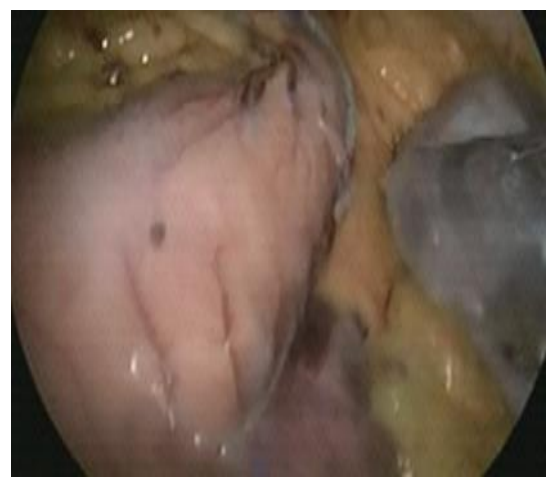

Figure [5]: Leak test was done by diluted methylene blue.

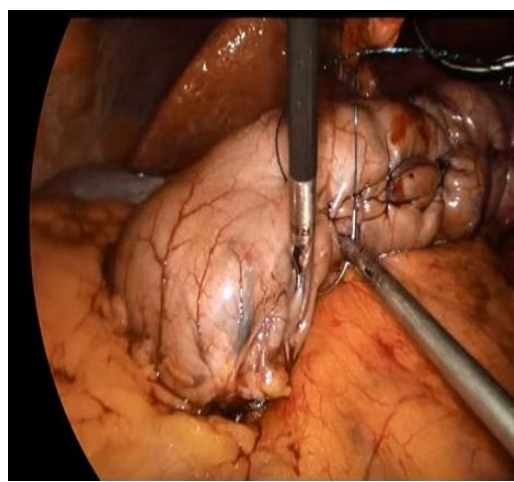

Figure [3]: The seconed row cover the $1^{\text {st }}$ row.

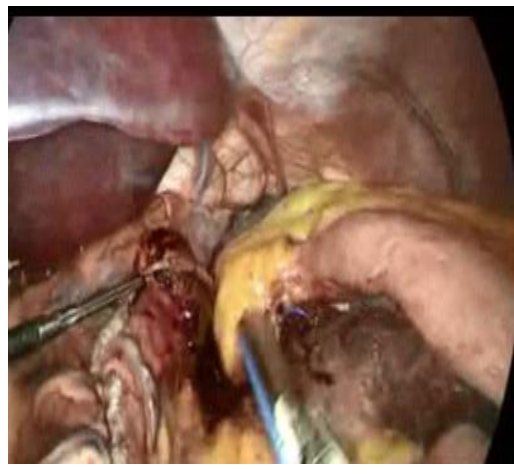

Figure [6]: Gastic pouch 


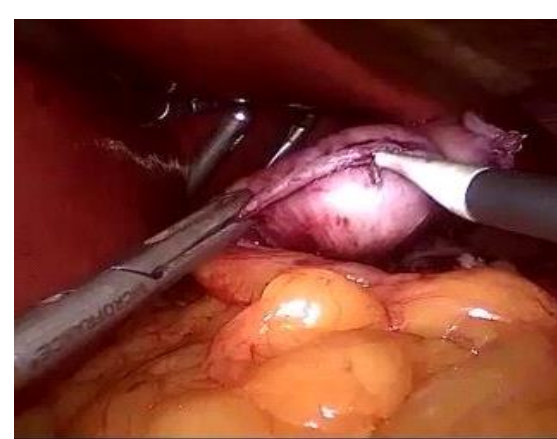

Figure [7]: A vessel sealing device was used to create gastrostomy.

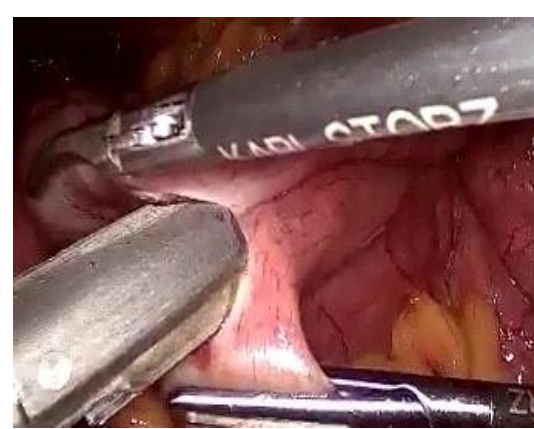

Figure [8]: The linear stapler was passed and fired to create anastomosis.
Post-operative assessment: If needed, patients were admitted to intensive unit for one day. At the first post-operative day, oral intake was started in the form of sips of clear water and progressed to a low caloric sugar free clear liquids including juice. Most patients were discharged from hospital by the second or third day after the surgery. The feeding after operation was determined as proceeding from customized liquid feeding for two weeks, to the gradual replacement to solid foods gradually. Patients were instructed for: Intake of proton pump inhibitors for one month, intake of low molecular heparin subcutaneously for one week for risky patients, good hydration, proper chewing and swallowing techniques, dietary intake to be in the form of divided meals, and avoidance of sweet eating and high caloric meals.

Follow-up: Evaluation of the early postoperative complications during the first two weeks then follow up of patients at $1,3,6,12$ months for late postoperative complications, changes in co morbidities [as hypertension, diabetes mellitus, arthritis], percentage of excess weight loss .

Statistical Analysis: Data was analyzed using SPSS [Statistical program for Social Sciences] version 15 [SPSS Inc., Chicago, Illionis, USA] Qualitative [categorical] data were expressed as ferquancy and percentage. Quantitative data were expressed as mean \pm standerd devision [SD]. The following testes were used: Chi-squre test, for comparison between non -parametric data, and one way analysis of variance with least signficant differnce [LSD] as Post Hoc analysis for comparison between multiple means. In all tables, P0: stastical significance between all groups. P1: statistical comparison between GCP and LSG. P2: statistical significance between GCP and By Pass. P3: statistical significance between LSG and By Pass. $P$ value $<0.05$ was set as level of signficance.

\section{RESULTS}

As regard to Patient demographics, Group A [LGCP] included 10 Patients; the mean patients' age was [36.4 \pm 8.75 years] ranging between 20-50 years and gender distribution was 6 females [60\%] and 4 males [40\%]. The mean BMI at time of surgery was $45.3 \pm 5.53 \mathrm{~kg} / \mathrm{m}^{2}$ [BMl ranged from 38 to $52 \mathrm{Kg} / \mathrm{m}^{2}$ ]. In addition, group B [LSG] included 10 Patients, the mean patients' age was $[45.3 \pm 5.3$ years] ranging between 22-50 years and gender distribution was 7 females [70\%] and 3 males [30\%]. The mean BMI at time of surgery was $46.0 \pm 4.8 \mathrm{~kg} / \mathrm{m}^{2}$ [BMl ranged from 39 to $53 \mathrm{Kg} / \mathrm{m}^{2}$ ]. Furthermore, in group C [LRYGBP], the mean patients' age was [43.5 \pm 7.09 years] ranging between 28-52 years and gender distribution was 8 females [80\%] and 2 males [20\%]. The mean BMI at time of surgery was $46.4 \pm 5.7 \mathrm{~kg} / \mathrm{m}^{2}$ [BMl ranged from 39 to $55 \mathrm{Kg} / \mathrm{m}^{2}$ ]. The comorbidities in the GCP group were one patient [10\%] had type 2 diabetes mellitus [T2DM], four [40\%] had arthritis and two [20\%] had hypertension. The comorbidities in the LSG group were two patients had T2DM, two [20\%] had arthritis, three [30\%] had hypertension and one [10\%] had sleep apnea syndrome [SAS]. The comorbidities in the Bypass group were three patients [30\%] had T2DM, three [30\%] had arthritis, two [20\%] had hypertension and one [10\%] had SAS. When comparing the comorbidities in the studied groups there were no statistical significant difference [Table 1]. The operative time in the GCP group ranged from 90 to 120 with the mean operative time $118+19.7$ minutes. The operative time in the LSG 
group ranged from 60 to 120 with the mean operative time $97.5+21.5$ minutes. The operative time in the Bypass group ranged from 100 to 130 with the mean operative time $120.8+12.1$ minutes .When comparing the means of the studied groups there were statistical significant difference as regard the operative time, which was significantly decreased in group B when compared to either group A or group $C$, while the difference between groups $A$ and $C$ was statistically non-significant. Follow up [months] was no significantly differ between studied groups. In addition, no significant difference was reported between groups regarding intraoperative bleeding or postoperative complications [Table 2].

Regarding estimated body weight loss [EBWL] at the second week postoperative, there was significant increase of EBWL in groups $B$ and $C$ when compared to group $A[5.75 \pm 3.96$ and $8.4 \pm 5.54$ vs $1.15 \pm 0.81$ respectively] while the difference between groups $B$ and $C$ was statistically non-significant. At the third months, there was significant increase of EBWL in group $C$ [19.2 \pm 6.37$]$ when compared to either group $A[10.5 \pm 4.48]$ or group $B$ [14.2 \pm 4.24$]$, and the difference between groups $B$ and $C$ was statistically significant. Typical situation was observed at 1.5 years of follow up, while at the 6 months follow up, EBWL of group $C$ significantly increased when compared to groups $A$ or $B$, while the difference between groups $B$ and $C$ was notsignificant, and at one year, the difference between groups $A$ and $B$ was statistically significant [Details were presented in Table 3]. Failure after bariatric surgery is defined as achieving or maintaining less than $50 \%$ of excess weight loss [EWL] over 18 to 24 months or a body mass index [BMI] of greater than
35. The number of cases that failed after operation in the GCP group were four out of ten patients [40\%]. In the LSG group were one out of ten patients [10\%]. In the By Pass group there were no failure. When comparing the number of cases that failed after operation in the studied groups there were a statistical significant difference between the studied groups regarding failure. These results indicate that LRYGB has a superior metabolic effect compared with LSG and LGCP. The number of cases that died after operation was only one patient in the By Pass group [10\%] due to septicemia, while there were no mortality in the other two groups [Table 4]. The comorbidities in the GCP group were one patient [10\%] had type 2 diabetes mellitus [T2DM], four [40\%] had arthritis and two [20\%] had hypertension. The comorbidities in the LSG group were two patients had T2DM, two [20\%] had arthritis, three [30\%] had hypertension and one [10\%] had SAS. The comorbidities in the By Pass group were three patients [30\%] had T2DM, three [30\%] had arthritis, two [20\%] had hypertension and one [10\%] had SAS. The effect of GCP surgery on co-morbidities in GCP group were improvement in T2DM [1\%], Arthritis [40\%] and HTN [20\%] in the 1 st six months but regression occurs at 1.5 years [Table 5].

The effect of LSG surgery on co-morbidities in LSG group were improvement in T2DM [20\%], Arthritis [20\%], HTN [20\%] and SAS [10\%] in the $1^{\text {st }}$ six months and followed by cure at 1.5 years. The effect of Gastric by-pass surgery on co-morbidities in Gastric by-pass group were improvement in T2DM [20\%], Arthritis [20\%], HTN [20\%] and SAS [10\%] in the $1^{\text {st }}$ six months and followed by cure at 1.5 years [Table 6].

Table [1]. Patient's characters and obesity related comorbidities among studied groups.

\begin{tabular}{|c|c|c|c|c|c|}
\hline \multicolumn{2}{|c|}{ Variables } & Group A [LGCP] & Group B [LSG] & Group C [By Pass] & P-value \\
\hline \multicolumn{2}{|l|}{ Age[years] } & $36.4 \pm 8.75$ & $39.2 \pm 9.34$ & $43.5 \pm 7.09$ & 0.2 \\
\hline \multicolumn{2}{|l|}{ Gender [M - F] } & $4[40 \%]-6[60 \%]$ & $3[30 \%]-7[70 \%]$ & $2[20 \%]-8[80 \%]$ & 0.6 \\
\hline \multicolumn{2}{|l|}{$\mathrm{BMI}\left[\mathrm{kg} / \mathrm{m}^{2}\right]$} & $45.3 \pm 5.3$ & $46.0 \pm 4.8$ & $46.4 \pm 5.7$ & 0.9 \\
\hline \multirow{4}{*}{$\begin{array}{l}\text { Obesity-related } \\
\text { comorbidities }\end{array}$} & DM & $1[10 \%]$ & $2[20 \% 0$ & $3[30 \%]$ & \multirow[t]{4}{*}{0.8} \\
\hline & Arthritis & $4[40 \%]$ & $2[20 \%]$ & $3[30 \%]$ & \\
\hline & HTN & $2[20 \%]$ & $3[30 \%]$ & $2[20 \%]$ & \\
\hline & SAS & $0[0 \%]$ & $1[10 \%]$ & $1[10 \%]$ & \\
\hline
\end{tabular}

LGCP: laparoscopic greater curvature plication; LSG: laparoscopic sleeve gastrectomy; BMI: body mass index; DM: diabetes mellitus; HTN: hypertension; SAS: sleep apnea syndrome. 
Table [2]. Comparison between the three groups as regard operative time, intra-operative bleeding, follow up time and postoperative complications

\begin{tabular}{|c|c|c|c|c|c|}
\hline & & $\begin{array}{c}\text { Group }[A] \\
\text { GCP } \\
{[N=10]}\end{array}$ & $\begin{array}{c}\text { Group[B] } \\
\text { LSG } \\
{[N=10]}\end{array}$ & $\begin{array}{l}\text { Group[C] } \\
\text { By Pass } \\
{[N=10]}\end{array}$ & P-value \\
\hline \multirow{2}{*}{$\begin{array}{l}\text { Operative time } \\
\text { [min] }\end{array}$} & Mean & 118.0 & 97.5 & 120.8 & \multirow{2}{*}{$\begin{array}{l}P 0=0.02^{*} ; P 1=0.02^{*} \\
P 2=0.7 ; P 3=0.009^{*}\end{array}$} \\
\hline & $\pm S D$ & 19.7 & 21.5 & 12.1 & \\
\hline \multirow{2}{*}{$\begin{array}{l}\text { Follow up } \\
\text { [months] }\end{array}$} & Mean & 18.7 & 16.9 & 15.3 & \multirow[t]{2}{*}{$\mathrm{P} 0=0.3$} \\
\hline & $\pm S D$ & 2.8 & 4.4 & 6.1 & \\
\hline \multirow[t]{2}{*}{ Intraoperative Bleeding. } & No & $10[100 \%]$ & $9[90 \%]$ & $8[8 \%]$ & \multirow[t]{2}{*}{$P 0=0.3$} \\
\hline & Yes & $0[0 \%]$ & $1[10 \%]$ & $2[20 \%]$ & \\
\hline \multirow{7}{*}{$\begin{array}{l}\text { Postoperative } \\
\text { complications }\end{array}$} & Bleeding & $0[0 \%]$ & $1[10 \%]$ & $2[20 \%]$ & 0.3 \\
\hline & Nausea & $4[40 \%]$ & $2[20 \%]$ & $0[0 \%]$ & 0.08 \\
\hline & Vomiting & $3[30 \%]$ & $2[20 \%]$ & $0[0 \%]$ & 0.2 \\
\hline & Stricture & $0[0 \%]$ & $1[10 \%]$ & $0[0 \%]$ & 0.4 \\
\hline & Ulcer & $0[0 \%]$ & $0[0 \%]$ & $1[10 \%]$ & 0.4 \\
\hline & Leak & $0[0 \%]$ & $1[10 \%]$ & $2[20 \%]$ & 0.3 \\
\hline & Cholelithiasis & $1[10 \%]$ & $2[20 \%]$ & $3[30 \%]$ & 0.5 \\
\hline
\end{tabular}

P0: one-way analysis of variance [Comparison between the three groups]; p1: comparison between group A and group B; P2: comparison between group A and group C; P3: comparison between group B and group C; * significant difference.

Table [3]. Comparison between studied groups as regard EBWL.

\begin{tabular}{|c|c|c|c|c|c|}
\hline & & $\begin{array}{c}\text { Group }[A] \\
\text { GCP } \\
{[N=10]}\end{array}$ & $\begin{array}{c}\text { Group [B] } \\
\text { LSG } \\
{[N=10]}\end{array}$ & $\begin{array}{c}\text { Group[C] } \\
\text { ByPass } \\
{[\mathrm{N}=10]}\end{array}$ & P-value \\
\hline \multirow[t]{2}{*}{$2^{\text {nd }}$ week } & Mean & 1.15 & 5.75 & 8.4 & \multirow{2}{*}{$\begin{array}{c}\mathrm{P} 0=0.001^{* *} ; \mathrm{P} 1=0.02^{*} \\
\mathrm{P} 2<0.001^{*} ; \mathrm{P} 3=0.1\end{array}$} \\
\hline & $\pm S D$ & 0.81 & 3.96 & 5.54 & \\
\hline \multirow[t]{2}{*}{$3^{\text {rd }}$ month } & Mean & 10.5 & 14.2 & 19.2 & \multirow{2}{*}{$\begin{array}{c}\mathrm{P} 0=0.003^{* *} ; \mathrm{P} 1=0.1 \\
\mathrm{P} 2=0.001^{* *} ; \mathrm{P} 3=0.04^{*}\end{array}$} \\
\hline & $\pm S D$ & 4.48 & 4.24 & 6.37 & \\
\hline \multirow[t]{2}{*}{$6^{\text {th }}$ month } & Mean & 20 & 40 & 50.9 & \multirow{2}{*}{$\begin{array}{c}\mathrm{P} 0<0.001^{*} ; \mathrm{P} 1=0.002^{*} \\
\mathrm{P} 2<0.001^{*} ; \mathrm{P} 3=0.07\end{array}$} \\
\hline & $\pm S D$ & 7.82 & 15.63 & 14.13 & \\
\hline \multirow[t]{2}{*}{$1^{\text {st }}$ year } & Mean & 36.3 & 52 & 71 & \multirow{2}{*}{$\begin{array}{l}\mathrm{P} 0=0.001^{* *} ; \mathrm{P} 1=0.07 \\
\mathrm{P} 2<0.001^{*} ; \mathrm{P} 3=0.03^{*}\end{array}$} \\
\hline & $\pm S D$ & 16.96 & 22.01 & 16.39 & \\
\hline \multirow[t]{2}{*}{1.5 year } & Mean & 45.6 & 70.5 & 85.7 & \multirow{2}{*}{$\begin{array}{l}\mathrm{P} 0<0.001^{*} ; \mathrm{P} 1<0.001^{*} \\
\mathrm{P} 2<0.001^{*} ; \mathrm{P} 3=0.02^{*}\end{array}$} \\
\hline & $\pm S D$ & 13.06 & 15.89 & 9.39 & \\
\hline
\end{tabular}

P0: one-way analysis of variance [Comparison between the three groups]; $p 1$ : comparison between group $A$ and group $B ; P 2$ : comparison between group A and group C; P3: comparison between group B and group C; * significant difference.

Table [4]. Comparison between studied groups as regard failure and mortality.

\begin{tabular}{|c|c|c|c|c|c|}
\hline \multicolumn{2}{|c|}{ Variables } & Group[A] GCP & Group[A] LSG & Group[C] Bypass & P-value \\
\hline \multirow{2}{*}{ Failure } & No & $6[60 \%]$ & $9[90 \%]$ & $10[100 \%]$ & $0.04^{*}$ \\
\cline { 2 - 5 } & Yes & $4[40 \%]$ & $1[10 \%]$ & $0[0 \%]$ & \\
\hline \multirow{2}{*}{ Mortality } & No & $10[100 \%]$ & $10[100 \%]$ & $9[90 \%]$ & 0.4 \\
\cline { 2 - 5 } & Yes & $0[0 \%]$ & $0[0 \%]$ & $1[10 \%]$ & \\
\hline
\end{tabular}

* significant difference

Table [5]. Effect of GCP on co-morbidities.

\begin{tabular}{|c|c|c|c|c|c|c|}
\hline \multicolumn{2}{|c|}{} & $2^{\text {nd }}$ week & $3^{\text {rd }}$ month & $6^{\text {th }}$ month & 1 st year & 1.5 year \\
\hline DM & Improved & $1[10 \%]$ & $1[10 \%]$ & $1[10 \%]$ & $0[0 \%]$ & $0[0 \%]$ \\
\cline { 2 - 7 }$[\mathrm{N}=1]$ & Regressed & $0[0 \%]$ & $0[0 \%]$ & $0[0 \%]$ & $1[10 \%]$ & $1[10 \%]$ \\
\hline Arthritis & Improved & $2[20 \%]$ & $3[30 \%]$ & $4[40 \%]$ & $2[20 \%]$ & $0[0 \%]$ \\
\cline { 2 - 7 }$[\mathrm{N}=4]$ & Regressed & $2[20 \%]$ & $1[1 \%]$ & $0[0 \%]$ & $2[20 \%]$ & $4[40 \%]$ \\
\hline HTN & Improved & $1[1 \%]$ & $2[2 \%]$ & $2[2 \%]$ & $1[1 \%]$ & $0[0 \%]$ \\
\cline { 2 - 7 }$[\mathrm{N}=2]$ & Regressed & $1[1 \%]$ & $0[0 \%]$ & $0[0 \%]$ & $1[1 \%]$ & $2[2 \%]$ \\
\hline
\end{tabular}

DM: Diabetes mellitus; HTN: hypertension. 
Sayyouh AS, et al.

Table [6]. Effect of LSG and by pass on co-morbidities.

\begin{tabular}{|c|c|c|c|c|c|c|c|c|c|c|c|}
\hline \multicolumn{2}{|l|}{ Variables } & \multicolumn{2}{|c|}{$2^{\text {nd }}$ week } & \multicolumn{2}{|c|}{$3^{\text {rd }}$ month } & \multicolumn{2}{|c|}{$6^{\text {th }}$ month } & \multicolumn{2}{|c|}{$1^{\text {st }}$ year } & \multicolumn{2}{|c|}{1.5 year } \\
\hline & & LSG & Bypass & LSG & Bypass & LSG & Bypass & LSG & Bypass & LSG & Bypass \\
\hline \multirow[t]{2}{*}{ DM } & Improved & 2 & 3 & 2 & 3 & 2 & 2 & 1 & 1 & 0 & 0 \\
\hline & Cured & 0 & 0 & 0 & 0 & 0 & 1 & 1 & 2 & 2 & 3 \\
\hline \multirow[t]{2}{*}{ Arthritis } & Improved & 2 & 3 & 0 & 3 & 2 & 2 & 1 & 1 & 0 & 0 \\
\hline & Cured & 0 & 0 & 0 & 0 & 0 & 1 & 1 & 2 & 2 & 3 \\
\hline \multirow[t]{2}{*}{ HTN } & Improved & 3 & 2 & 3 & 2 & 2 & 2 & 1 & 1 & 0 & 0 \\
\hline & Cured & 0 & 0 & 0 & 0 & 0 & 0 & 2 & 1 & 3 & 2 \\
\hline \multirow[t]{2}{*}{ SAS } & Improved & 1 & 1 & 1 & 1 & 1 & 1 & 0 & 0 & 0 & 0 \\
\hline & Cured & 0 & 0 & 0 & 0 & 0 & 0 & 1 & 1 & 1 & 1 \\
\hline
\end{tabular}

DM: Diabetes mellitus; HTN: hypertension; SAS: sleep apnea syndrome

\section{DISCUSSION}

In the current study, a three surgical procedures were used 1] Laparoscopic greater curvature plication [GCP]. 2] Laparoscopic Sleeve gastrectomy [LSG]. 3] Laparoscopic Gastric bypass. Results of the present work are comparable to those reported by Verdi et al.[19]. In all groups, there was female sex predilection, which comparable to Boza et al.[20]. This may be explained by the fact that, females are more prone to psychosocial problems, and concerned about the cosmetic effects of obesity.

Previous work indicated that, there was a rise in the risk of operative mortality and perioperative complications with increased BMls, as the abdominal wall is relatively thick in comparison to a small abdominal cavity, thereby increasing the risk of intraabdominal complications. This category of patients are also at increased risk of developing thromboembolic complications after surgery ${ }^{[21]}$. This could explain the high complications rate bserved with different barriatric procedures. Chouillard et al.[22] reported nausea and vomiting in 20\% after LGCP and $7.5 \%$ after LSG. Abdelbaki et al.[23] noted that $15 \%$ had nausea and vomiting in LGCP group, and $1.5 \%$ in LSG group. The key difference between LSG and LGCP is the presence of the endoluminal fold. Skrekas et al.[24] reported that the nausea and vomiting improved greatly after the modified LGCP technique by constructing a double or triple plication of the apposed gastric wall than the first row of stitches.

Gastrointestinal $[\mathrm{Gl}]$ leak after bariatric surgery is not an uncommon complication and one that can be expected to occur at some point in every bariatric surgeon's experience ${ }^{[25]}$. In the current study the incidence of leak was 10\% for LSG group, $20 \%$ for
LRYGB and managed by conservative measures in the form of ultrasound-guided aspiration, inseration of drain and stent,while one patient needed re exploration. The reported incidence in literatures varies according to the procedure; LGBP 0.7$5.3 \%[26-27]$, and for LSG $1.1-7.1^{[28-30]}$. The esophagogastric $[E G]$ junction has been reported as the usual site of leak after LSG[28,30]. Particular attention should be paid to this area at the time of staple firings. It is important to use staples of an adequate height and to avoid stapling the esophagus.

In our study, there were 10\% mortality in Bypass group due to septicemia. Giuliani et al. [31] reported that, acute leakages are the most hazardous complication with potentially fatal outcome and there are no standardized guidelines for its management.

The leak usually occurs at the proximal or the distal ends of the staple line. Proximal gastric leaks, however, represent more than $90 \%$ of post-LSG leaks. Gagner et al.[32] reported that, mechanical causes are attributed to high intragastric pressure in the constructed sleeve due to the mechanical obstruction by L-shaped sleeve, physiologic pyloric obstruction, haematoma or oedema formation, too small bougie size or reinforcing sutures causing excessive narrowing. They are responsible for leaks in the first two postoperative days. They added that, tissue causes are responsible for leaks up to the sixth post-operative day. Reports documented an average incidence of $1.1 \%$ for post-LSG leaks.

Complications following LRYGB includes anastomotic leak [0.5-5\%], gastrointestinal haemorrhage [0.4-4\%], venous thrombo-embolism $[<1.3 \%]$, intestinal obstruction and internal hernias [1.1-10.5\%], anastomotic strictures [2-16\%], 
marginal ulcers [0.7-5.1\%] and nutritional deficiencies [3-52\%][33].

In the current study the cases that had complications in the LSG group were one patient $[10 \%]$ had bleeding and in the Bypass group were two patients [20\%] had bleeding. It was reported that the incidence of bleeding after obesity surgery ranges from 0.6 to $4 \%$ [34]. The small number of cases in each group could be resposible for exaggerated rate of complications. Stapling through a thick, vascular gastric wall can be followed by considerable amount of intra as well as extra-luminal [intra-peritoneal] bleeding. Post-LSG bleeding rated $2.7 \%$ [19 among 686 patients][35].

Regarding EWL in the LGP, results are of the present study are comparable to previous studies. For example, Ramos et al. ${ }^{[11]}$ found that, the mean percentage EWL was $20 \%$ EWL at 1 month [42 patients], $32 \%$ EWL at 3 months [33 patients], $48 \%$ EWL at 6 months [20 patients], $60 \%$ EWL at 12 months [ 15 patients], and $62 \%$ EWL at 18 months [ 9 patients]. In the line with the present study, Talebpour et al.[36], published a case series involving 800 patients, with an average time of follow up of 5 years. The mean excess weight loss was $70 \%$ after 24 months, and $55 \%$ after 5 years. The authors concluded that the percentage of EWL in LGCP is comparable to other restrictive methods as AGB and vertical banded gastroplasty, with $1.6 \%$ of complications, $31 \%$ weight regain, with a lower financial cost. In addition, a study focused on weight loss and type 2 diabetes outcomes, LGCP was performed in 55 morbidly obese diabetic patients, with a 1 year follow-up. BMI ranged from 35 to 52 $\mathrm{kg} / \mathrm{m}^{2}$ [mean $43.5 \mathrm{~kg} / \mathrm{m}^{2}$ ]. Mean EWL was $35 \%$ [30$65 \%$ ] after 12 months, with a mean BMl of $38 \mathrm{~kg} / \mathrm{m}^{2}$. A total of $23 \%$ of patients stopped losing weight 6 months after the procedure, and $11 \%$ began regaining about $14 \%$ [12-20\%] of their EWL 9 months after the procedure.

Weight loss achieved after LSG is variable, but most studies report that it is comparable to that achieved by gastric bypass and better than the weight loss achieved following gastric banding. In addition, a single surgeon experience with 500 sleeve gastrectomy with 3-year follow-up showed that the mean EBWL was $76 \%, 71 \%$, and $73 \%$ at
12, 24, 36 months, respectively[37]. A study comparing LSG with laparoscopic adjustable gastric banding [LAGB] and laparoscopic Roux-en-Y gastric bypass [LRYGB] found that weight loss at one year following LSG was $13 \%$ lower than that after LRYGB, but $77 \%$ higher than the weight loss achieved through gastric banding[38].

Regarding weight loss in the by-pass group. The longest running randomized controlled trial comparing RYGB and LAGB presented 10 year follow up data showed superior excess weight loss with RYGB compared to LAGB [76.2\% vs. 46.2 $\%$ ] [39]. RYGB results in significant early weight loss, which is maintained in the longer term. Most patients can expect to lose more than $50 \%$ of their excess weight and an average excess weight loss of more than $70 \%$ can be expected in the first 12 months after surgery[40].

Failure after bariatric surgery is defined as achieving or maintaining less than $50 \%$ of excess weight loss [EWL] over 18 to 24 months or BMI greater than $35^{[41]}$. In line with this study Verdi et al.[19], reported insufficient weight loss [EWL<50\%] and were in $60 \%$ of cases after LGCP [27 patients] and in $8.8 \%$ of cases after LSG [4 patients]. Skrekas et al. [24], also reported a failed operation $[\% \mathrm{EWL}<30 \%]$ in $6 \%$ of patients, and an insufficient weight loss [\% EWL $<50 \%$ ] in greater than $21 \%$ of patients underwent LGCP.

In agreement with the present study, there were no weight regain in the $L S G$ and the gastric bypass patient in the results that were obtained by Kakoulidis et al. [42]. It has been reported that the most frequent causes of death in bariatric surgery are pulmonary embolism, cardiac or respiratory failure and gastric fistula[43]. In the current study, the number of cases that died after operation was only one patient in the Bypass group [10\%] du to septicemia, while there were no mortality in the other two groups.

As regard comorbidities, improvement is defined as a reduction in medication use; resolution is defined as complete cessation and biochemical resolution ${ }^{[44]}$. In line with the current study a study focused on weight loss and type 2 diabetes outcomes, LGCP was performed in 55 morbidly obese diabetic patients, with a 1 year follow-up. 
Mean $\mathrm{HbA} 1 \mathrm{c}$ was $7.5 \%$ [5.5-8 \%] after 12 months. All patients were on oral antidiabetic medications preoperatively, and none had more than 5 years of disease. No patients stopped their diabetes medications after surgery [41]. However, a published multicenter, international study on influence of LGCP on T2DM suggests that metabolic effects of LGCP are positioned in between adjustable gastric banding and sleeve gastrectomy. Thus, LGCP appears to be more effective on T2DM than gastric banding, however slightly less effective than sleeve gastrectomy[45].

Hypertension resolution was defined as normal blood pressure [diastolic $<80 \mathrm{mmHg}$ and systolic $<140 \mathrm{mmHg}$ ] in the absence of antihypertensive drugs ${ }^{[46,47]}$. In line with this study, Shen et al. ${ }^{[14]}$, reported $66.7 \%$ and $75 \%$ hypertension remission after 6 months in LGCP and LSG, respectively and the improvement was $33.4 \%$ and $25 \%$ of hypertension 6 months after LGCP and LSG, respectively. Abdelbaki, et al. [23] reported $60 \%$ and $58 \%$ hypertension resolution one year post LGCP and LSG, respectively. On the other hand the improvement was $30 \%$ and $25 \%$ one year post LGCP and LSG, respectively.

In the terms of sleep apnea syndrome in line with the present study Lakdawala et al. ${ }^{[48]}$ found that the resolution of sleep apnea at 1 year was comparable in both LSG and LRYGB group and the resolution percentage in both groups was $100 \%$.

In a systematic review, it was found that in $75 \%$ of patients with sleep apnea had at least an improvement in their sleep apnea after bariatric surgery. Laparoscopic Biliopancreatic Diversion [BPD] surgery was the most successful procedure in improving or resolving obstructive sleep apnea, with laparoscopic adjustable gastric banding being the least. Improvements were seen regardless of the specific type of sleep apnea[49]. Ramos et al. [45] concluded that, the results of LGCP in terms of weight loss are lower than those achieved with sleeve gastrectomy; percentage of EWL in LGCP is comparable to adjustable gastric band. In long-term can be observed insufficient weight loss, weight regain and dilatation of the gastric pouch. As this conclusion supports the finding in the present study.

In conclusion, although our study had some limitations, such as the low number of patients, the simple study design and the short follow up period, the results demonstrated that LGCP is lesser to LSG and LGBS as procedure for the weight loss, despite of it's less cost. As well as, the LGCP had higher complications, reoperations and weight gains. Both LSG and LGBS showed comparable outcomes in the comorbidity remission or improvement during follow up.

Financial and Non-financial Relationships and Activities of Interest

None to disclose

\section{REFERENCE}

1. Kawada T. Bariatric surgery in patients with type 2 diabetes mellitus. Ann Surg. 2017 Dec; 266 [6]: e58. [DOl: 10.1097/SLA.0000000000001379].

2. Bambs C, Cerda J, Escalona A. Morbid obesity in a developing country: The Chilean experience. Bull World Health Org. 2008; 86 [10]:813-814. [DOI: 10.2471/ blt.07. 048785].

3. DeMaria EJ. Bariatric surgery for morbid obesity. N Engl J Med. 2007; 356[21]:2176-83. [DOI: 10.1056/NEJMct 067019].

4. Nocca D, Frering V, Gallix B, de Seguin des Hons C, Noël $P$, Foulonge MA, Millat $B$, Fabre JM. Migration of adjustable gastric banding from a cohort study of 4236 patients. Surg Endosc. 2005; 19[7]:947-950. [DOI: 10.1007/s00464-004-2183-6].

5. Baltasar A, Bou R, Bengochea M, Serra C, Cipaqauta L. Use of a Roux limb to correct esophagogastric junction fistulas after sleeve gastrectomy. Obesity Surg. 2007; 17[10]:1408-1410. [DOI: 10.1007/s11695-007-9222-z].

6. Bohdjalian A, Langer FB, Shakeri-Leidenmühler $S$, Gfrerer L, Ludvik B, Zacherl J, Prager G. Sleeve gastrectomy as sole and definitive bariatric procedure: 5 year results for weight loss and ghrelin. Obes Surg. 2010; 20:535-540. [DOI: 10.1007/s11695-009-0066-6].

7. Haris AK, Gianluca B. Bariatric surgery: Techniques, outcomes and complications: Curr Anaesth Crit Care 2010; 21: 31-38. [DOI: 10.1016/j.cacc.2009.10.005].

8. Gluck B, Movitz B, Jansma S, Gluck J, Laskowski K. Laparoscopic sleeve gastrectomy is a safe and effective bariatric procedure for the lower BMI [35.0-43.0 kg/m2] population. Obes Surg. 2011; 8: 1168-71. DOI: 10.1007/s11695-010-0332-7].

9. Talebpour M, Amoli BS. Laparoscopic total gastric vertical plication in morbid obesity. J Laparoendosc Adv Surg Tech A. 2007; 17[6]:793-8. [DOI: 10.1089/lap. 2006. 0128].

10. Brethauer SA, Harris JL, Kroh M, Schauer PR. Laparoscopic Greater Curvature Plication for the 
treatment of severe obesity. Surg Obes Relat Dis. 2011; 7[1]:15-22. [DOI: 10.1016/ j. soard.2010.09.023].

11. Ramos A, Galvao Neto M, Galvao M, Evangelista LF, Campos JM, Ferraz A. Laparoscopic greater curvature plication: initial results of an alternative restrictive bariatric procedure. Obes Surg. 2010; 20[7]: 913-8. [DOI: 10.1007/ s11695-010-0132-0].

12. Lim RB, Blackburn GL, Jones DB. Benchmarking best practices in weight loss surgery. Curr Probl Surg. 2010; 47[2]:79-174. [DOI: 10.1067/ j.cpsurg. 2009.11.003].

13. Lomanto D, Lee WJ, Goel R, Lee JJ, Shabbir A, So JB, et al. Bariatric Surgery in Asia in the Last 5 Years [20052009]. Obes Surg. 2012; 22 [3]: 502-6. [DOI: 10.1007/s11695-011-0547-2].

14. Shen D, Ye H, Ji Y, Zhan X, Zhu J, Wang Y. Comparison of short-term outcomes between laparoscopic greater curvature plication and laparoscopic sleeve gastrectomy. Surg Endosc. 2013; 27[8]:2768-74. [DOI: 10.1007/ s00464-013-2805-y]

15. Klok MD, Jakobsdottir S, Drent ML. The role of leptin and ghrelin in the regulation of food intake and body weight in humans: Review. Obes Rev. 2007; 8:21-34. [DOl: 10.1111/j.1467-789X.2006.00270.x].

16. Frezza EE, Chiriva-Internati M, Wachtel MS. Analysis of the results of sleeve gastrectomy for morbid obesity and the role of ghrelin. Surg Today 2008; 38:481. [DOI: 10.1007/s00595-007-3648-8].

17. Franco JV, Ruiz PA, Palermo, Gagner M. A review of studies comparing three laparoscopic procedures in bariatric surgery: Sleeve gastrectomy, Roux-en-y gastric bypass and adjustable gastric banding. Obes Surg. 2011; 21:1458-1468. [DOI: 10.1007/ s11695-011-0390-5].

18. Schauer PR, Bhatt DL, Kirwan JP, Wolski K, Brethauer SA, Navaneethan SD, et al. Bariatric surgery versus intensive medical therapy for diabetes-3-year outcomes. New Engl J Med. 2014; 370[21]: 2002-2013. [DOI: 10.1056/NEJMoa1401329].

19. Verdi D, Prevedello L, Albanese A, Lobba A, Foletto M. Laparoscopic gastric plication [LGCP] vs sleeve gastrectomy [LSG]: A single institution experience. Obes Surg. 2015; 25[9]: 1653-1657. [DOI: 10.1007/s11695-0151600-3]

20. Boza C, Gamboa C, Salinas J, Achurra P, Vega A, Pérez G. Laparoscopic Roux-en-Y gastric bypass versus laparoscopic sleeve gastrectomy: a case-control study and 3 years of follow-up. Surg Obes Relat Dis 2012; 8[3] 243-249. [DOI: 10.1016/j.soard.2011.08.023]

21. Fernandez Jr AZ, Demaria EJ, Tichansky DS, Kellum JM, Wolfe LG. Multivariate analysis of risk factors for death following gastric bypass for treatment of morbid obesity. Ann Surg. 2004; 239[5]:698-702. [DOl: 10.1097/01.sla.0000124295.41578.ab].
22. Chouillard E, SchoucairN, Alsabah S, Alkandari B, Montana L, Dejonghe B, Biagini J. Laparoscopic gastric plication [LGP] as an alternative to laparoscopic sleeve gastrectomy [LSG] in patients with morbid obesity: A preliminary, short-term, case-control study. Obes Surg. 2016; 26[6]: 1167-1172. [DOI: 10.1007/s11695-0151913-2].

23. Abdelbaki TN, Sharaan M, Abdelbaki NA, Khaled K. Laparoscopic gastric greater curvature plication versus laparoscopic sleeve gastrectomy: Early outcome in 140 patients. Surg Obes Relat Dis. 2014; 10:1141-6. [DOI: 10.1016/ j.soard. 2014.03.014].

24. Skrekas G, Antiochos K, Stafyla VK. Laparoscopic gastric greater curvature plication: results and complications in a series of 135 patients. Obes Surg. 2011; 21[11]: 1657-63. [DOI: 10.1007/s11695-011-0499$6]$.

25. Rosenthal RJ, Diaz AA, Arvidsson D, Baker RS, Basso N, Bellanger D, et al. International Sleeve Gastrectomy Expert Panel Consensus Statement: Best practice guidelines based on experience of $>12,000$ cases. Surg Obes Relat Dis. 2012; 8:8-19. [DOI: 10.1016/ j.soard. 2011.10.019].

26. Jacobsen HJ, Nergard BJ, Leifsson BG, Frederiksen SG, Agajahni E, Ekelund M, Hedenbro J, Gislason H. Management of suspected anastomotic leak after bariatric laparoscopic Roux-En-Y gastric bypass. $\mathrm{Br} \mathrm{J}$ Surg. 2014 Mar;101[4]:417-23. [DOI: 10.1002/bjs.9388]

27. Edholm D. Systematic Review and Meta-analysis of Circular- and Linear-Stapled Gastro-jejunostomy in Laparoscopic Roux-en-Y Gastric Bypass. Obes Surg. 2019 Jun; 29[6]:1946-1953. [DOI: 10.1007/s11695-01903803-w]

28. Casella G, Soricelli E, Rizzello M, Trentino P, Fiocca F, Fantini A, Salvatori FM, Basso N. Nonsurgical treatment of staple line leaks after laparoscopic sleeve gastrectomy. Obes Surg. 2009; 19[7]:821-6. [DOI: 10. 1007/s11695-009-9840-8]

29. Melissas J, Koukouraki S, Askoxylakis J, Stathaki M, Daskalakis M, Perisinakis K, Karkavitsas N. Sleeve gastrectomy: a restrictive procedure? Obes Surg. 2007; 17: 57-62. [DOI: 10.1007/s11695-007-9006-5].

30. Burgos AM, Braghetto I, Csendes A, Maluenda F, Korn O, Yarmuch J, Gutierrez L. Gastric leak after laparoscopic sleeve gastrectomy for obesity. Obes Surg. 2009; 19[12]: 1672-1677. [DOI: 10.1007/s11695-009-9884-9].

31. Giuliani A, Romano L, Marchese M, Necozione S, Cianca G, Schietroma M, Carlei F. Gastric leak after laparoscopic sleeve gastrectomy: management with endoscopic double pigtail drainage. A systematic review. Surg Obes Relat Dis. 2019;15[8]:1414-1419. [DOI: 10.1016/j.soard.2019.03.019] 
32. Gagner M, Deitel M, Erickson AL, Crosby RD. Survey on laparoscopic sleeve gastrectomy [LSG] at the Fourth International Consensus summit on sleeve gastrectomy. Obes Surg. 2013; 23[12]:2013-7. [DOI: 10.1007/ s11695013-1040-x].

33. Khwaja HA, Bonanomi G. Bariatric surgery: techniques, outcomes and complications. Curr Anaesth Crit Care 2010; 21[1]: 31-38. [DOI: 10.1016/j.cacc.2009.10.005].

34. Bakhos C, Alkhoury F, Kyriakides T, Reinhold R, Nadzam G. Early postoperative hemorrhage after open and laparoscopic roux-en-y gastric bypass. Obes Surg. 2009; 19[2]:153-7. [DOI: 10.1007/s11695-008-9580-1].

35. Weiner R A, El-Sayes I A, Weiner SR. LSG: Complications diagnosis and management. In Obesity, Bariatric and Metabolic Surgery: Springer, Cham, 2016 [pp. 259-276].

36. Talebpour M, Motamedi SM, Talebpour A, Vahidi H. Twelve-year experience of laparoscopic gastric plication in morbid obesity: Development of the technique and patient outcomes. Ann Surg Innov Res. 2012; 6[1]:7. [DOI: 10.1186/1750-1164-6-7].

37. Gibson SC, Le Page PA, Taylor CJ. Laparoscopic sleeve gastrectomy: Review of 500 cases in single surgeon an Australian practice. ANZ J Surg. 2015; 85[9]: 673-677. [DOI:10.1111/ans. 12483].

38. Carlin AM, Zeni TM, English WJ, Hawasli AA, Genaw JA, Krause KR, et al. The comparative effectiveness of sleeve gastrectomy, gastric bypass, and adjustable gastric banding procedures for the treatment of morbid obesity. Ann Surg. 2013; 257[5]: 791-797. [DOI: 10.1097/SLA. 0b013e3182879ded].

39. Angrisani L, Cutolo PP, Formisano G, Nosso G, Vitolo G. Laparoscopic adjustable gastric banding versus rouxen-y gastric bypass: 10-year results of a prospective, randomized trial. Surg Obes Relat Dis. 2013; 9[3]:40513. [DOI: 10.1016/ j.soard. 2012.11.011].

40. Carr RJ, Mahawar KK. Roux-en-Y Gastric Bypass: Outcomes. In Obesity, Bariatric and Metabolic Surgery, 2016 [pp. 231-238]: Springer, Cham.

41. Parikh M, Gagner M. Laparoscopic hiatal hernia repair and repeat sleeve gastrectomy for gastroesophageal reflux disease after duodenal switch. Surg Obes Relat Dis. 2008; 4[1]:73-75. [DOI: 10.1016/ j.soard.2007.07.014].
42. Kakoulidis TP, Karringer A, Gloaguen T, Arvidsson D. Initial results with sleeve gastrectomy for patients with class I obesity [BMI 30-35 Kg/m²]: Surg Obes Relat Dis. 2009; 5: 425-428. [DOI: 10.1016/ j.soard.2008.09.009].

43. Hamoui N, Anthone GJ, and Kaufman HS, Crookes PF. Sleeve gastrectomy in the high-risk patient. Obes Surg. 2006; 16:1445-1449. [DOI: 10.1381/096089206778 870157].

44. Lemanu DP, Srinivasa S, Singh PP, MacCormick AD, Ulmer S, et al. Single-stage laparoscopic sleeve gastrectomy: safety and efficacy in the super-obese. J Surg Res. 2012; 177: 49-54. [DOI: 10.1016/j.jss. 2012.01.011].

45. Bradnova O, Kyrou I, Hainer V, Vcelak J, Halkova T, Sramkova $\mathbf{P}$, et al. Laparoscopic greater curvature plication in morbidly obese women with type 2 diabetes: Effects on glucose homeostasis, postprandil triglyceridemia and selected gut hormones. Obes Surg. 2014; 24:718-26. [DOI: 10.1007/s11695-013-1143-4].

45. Ramos AC, de Paula PS, Campos JM. Laparoscopic Gastric Plication. In: Obesity. Bariatric and Metabolic Surgery: Springer, Cham, 2016: Pages 469-475, [DOI: 10.1007/978-3-319-04343-2].

46. Yip S, Plank LD, Murphy R. Gastric bypass and sleeve gastrectomy for type 2 diabetes: A systematic review and meta-analysis of outcomes. Obes Surg. 2013; 23[12]:1994 2003. [DOI: 10.1007/s11695-013-1030-z].

47. Salman K Al-Sabah, Sulaiman M Almazeedi, Shaimaa A. The Efficacy of Laparoscopic Sleeve Gastrectomy in Treating Adolescent Obesity. Obes Surg. 2015; 25:5054. [DOI: 10.1007/ s11695-014-1340-9].

48. Lakdawala MA, Bhasker A, Mulchandani D, Goel S, Jain S. Comparison between the results of laparoscopic sleeve gastrectomy and laparoscopic Roux-en-Y gastric bypass in the Indian population: a retrospective 1-year study. Obes Surg. 2010; 20[1]: 1-6. [DOI: 10.1007/ s11695-009-9981-9].

49. Sarkhosh K, Switzer NJ, El-Hadi M, Birch DW, Shi X, Karmali S. The impact of bariatric surgery on obstructive sleep apnea: A systematic review. Obes Surg. 2013; 23[3]:414-23. [DOI: 10.1007/s11695-012-0862-2]. 